\title{
Access to primary healthcare services and associated factors in urban slums in Nairobi-Kenya
}

Peter O. Otieno* ${ }^{*}$, Elvis O. A. Wambiya, Shukri M. Mohamed, Martin Kavao Mutua, Peter M. Kibe, Bonventure Mwangi and Hermann Pythagore Pierre Donfouet

\begin{abstract}
Background: Access to primary healthcare is crucial for the delivery of Kenya's universal health coverage policy. However, disparities in healthcare have proved to be the biggest challenge for implementing primary care in poorurban resource settings. In this study, we assessed the level of access to primary healthcare services and associated factors in urban slums in Nairobi-Kenya.

Methods: The data were drawn from the Lown scholars' study of 300 randomly selected households in Viwandani slums (Nairobi, Kenya), between June and July 2018. Access to primary care was measured using Penchansky and Thomas' model. Access index was constructed using principal component analysis and recorded into tertiles with categories labeled as poor, moderate, and highest. Generalized ordinal logistic regression analysis was used to determine the factors associated with access to primary care. The adjusted odds ratios (AOR) and 95\% confidence intervals were used to interpret the strength of associations.

Results: The odds of being in the highest access tertile versus the combined categories of lowest and moderate access tertile were three times higher for males than female-headed households (AOR 3.05 [95\% Cl 1.47-6.37]; $p<.05$ ). Households with an average quarterly out-of-pocket healthcare expenditure of $\geq$ USD 30 had significantly lower odds of being in the highest versus combined categories of lowest and moderate access tertile compared to those spending $\leq$ USD 5 (AOR 0.36 [95\% Cl 0.18-0.74]; $p<.05$ ). Households that sought primary care from private facilities had significantly higher odds of being in the highest versus combined categories of lowest and moderate access tertiles compared to those who sought care from public facilities (AOR 6.64 [95\% Cl 3.67-12.01]; $p<.001$ ).

Conclusion: In Nairobi slums in Kenya, living in a female-headed household, seeking care from a public facility, and paying out-of-pocket for healthcare are significantly associated with low access to primary care. Therefore, the design of the UHC program in this setting should prioritize quality improvement in public health facilities and focus on policies that encourage economic empowerment of female-headed households to improve access to primary healthcare.
\end{abstract}

Keywords: Access to primary healthcare, Universal health coverage, Urban slums, Penchansky and Thomas's model

\footnotetext{
* Correspondence: pootienoh@gmail.com

African Population and Health Research Center, APHRC Campus, 2nd Floor,

Manga Close, Off Kirawa Road, P.O. Box: 10787-00100, Nairobi, Kenya
}

(c) The Author(s). 2020 Open Access This article is licensed under a Creative Commons Attribution 4.0 International License, which permits use, sharing, adaptation, distribution and reproduction in any medium or format, as long as you give appropriate credit to the original author(s) and the source, provide a link to the Creative Commons licence, and indicate if changes were made. The images or other third party material in this article are included in the article's Creative Commons licence, unless indicated otherwise in a credit line to the material. If material is not included in the article's Creative Commons licence and your intended use is not permitted by statutory regulation or exceeds the permitted use, you will need to obtain permission directly from the copyright holder. To view a copy of this licence, visit http://creativecommons.org/licenses/by/4.0/. The Creative Commons Public Domain Dedication waiver (http://creativecommons.org/publicdomain/zero/1.0/) applies to the data made available in this article, unless otherwise stated in a credit line to the data. 


\section{Background}

Access to primary healthcare is widely acknowledged as key to reducing the global burden of morbidity and mortality [1-3]. In 1978, the World Health Organization launched the Alma Ata declaration in a bid to promote access to essential healthcare services while acknowledging health as "a foremost human right" [4]. While this agreement was ratified by a majority of low and middleincome (LMIC) countries, time has shown that the resolutions of the Alma Ata declaration remain unfulfilled globally [5]. In LMIC countries, access to primary care remains low [6]. Identifying the factors associated with access to primary healthcare in resource limited-settings is an essential undertaking, particularly, following the inclusion of universal health coverage (UHC) in the sustainable development goals [7]. In particular, access to primary healthcare services serves as an important proxy measure of UHC and thus can be used to evaluate the performance of a healthcare system and identify the untapped potential for advancing UHC [8].

Kenya typifies urban growth and slumization in subSaharan Africa. The majority (60-80\%) of urban slum dwellers in Kenya live in informal settlements characterized by poor sanitation and hygiene, overcrowding and poor housing, and inadequate public healthcare services $[9,10]$. Studies have also shown the burden of illness in urban informal settlements in Kenya tends to be high with poor coverage of effective preventive and therapeutic interventions [11-14]. The near absence of basic public amenities in slum settings in Kenya has resulted in the mushrooming of several small substandard clinics that are unable to offer integrated primary healthcare yet they serve a huge slum population [15]. This has negative implications on access to healthcare services among slum residents [16]. Even though the private health facilities have attempted to bridge the gap in demand for primary healthcare services in slum areas, previous studies have shown that they lack the capacity and do not guarantee service quality due to their profit-centric nature [17]. In spite of the recent efforts made by the Kenyan government to expand UHC, more evidence is needed on barriers and facilitators of access to healthcare services to improve coverage and performance of the primary healthcare system [18].

The objective of this study was to assess the factors associated with access to primary healthcare in urban slums in Nairobi, Kenya. Our study contributes to existing knowledge in two major ways. First, access to essential healthcare services is a critical indicator in the evaluation of UHC. Therefore, knowledge of healthcare services accessibility and associated factors in resourcepoor urban settings may be used in the planning and delivery of evidence-based interventions to optimize health service delivery and achieve sustainability. Second, using
Penchansky and Thomas' model of access to healthcare [19], we consider a broader analysis of multiple indicators of access to primary healthcare ranging from health insurance coverage, timeliness of care, distance to the nearest primary care center, availability of essential healthcare services, affordability, acceptability to quality of care and treatment procedures.

\section{Methods}

\section{Study design and setting}

The data for this study are drawn from the Lown scholars' survey on healthcare gaps in informal settlements conducted between June 2018 and July 2018 in Viwandani slums (Nairobi, Kenya). A total of 300 randomly selected households from the Nairobi Urban Health Demographic Surveillance System (NUHDSS) were surveyed in the Lown scholars' study. The respondents comprised adults aged 18 years and over who were either household heads or permanent household members. The design of the Lown scholars' study has been previously published [20].

\section{Data collection}

A structured interviewer-administered questionnaire was used to collect data from the respondents. The interview questions consisted of healthcare utilization patterns, health insurance coverage, timeliness of care, distance to the nearest primary care center, availability of essential healthcare services, affordability, acceptability, quality of care, and treatment procedure. Other questions included perceived health status, out-of-pocket healthcare expenditure, and average monthly expenditure on health insurance. The responses were electronically recorded in a tablet. Secondary data on socioeconomic status of the selected households were obtained from the latest NUHDSS data, which is run by the African Population and Health Research Center in Viwandani and Korogocho slum settlements.

\section{Research model}

Our study is underpinned by Penchansky and Thomas' theory of access to primary healthcare [19]. Previous studies in Nigeria [21] and Istanbul [22] have also adopted this model. Penchansky and Thomas' theory proposes a taxonomic definition of "access." This theory summarizes a set of specific metrics that describe the fit between the healthcare system and the general population. These metrics are; availability, accessibility, accommodation, affordability, and acceptability of healthcare services. In particular, Penchansky and Thomas' metrics of access form a formidable chain of access to primary care that is no stronger than its weakest link [19].

Using Penchansky and Thomas' theory, we conceptualized seven independent and interconnected dimensions 
of access. These dimensions are health insurance coverage, timeliness of care, distance to the nearest primary care center, availability, affordability, and acceptability of essential healthcare services, quality of care and treatment procedure. Health insurance coverage measures the extent of financial protection of patients from the unexpected or high cost of healthcare services, distance to the nearest primary care center measures geographic accessibility of healthcare services. Timeliness of care measures the level of responsiveness of the health facility to the needs of the patient. Affordability measures the relationship between the costs of healthcare services versus the willingness and the ability of the patient to pay for the services. Availability determines the presence of requisite healthcare resources, such as infrastructure, personnel, technology, and essential supplies needed to meet the healthcare needs of the patients. Quality of care and treatment procedure reflects the operational organization of the provider in a manner that meets the preferences of the patients. Acceptability measures the extent of comfortability of the patients with immutable characteristics of the healthcare service provider such as sex, age, ethnicity, and social class.

\section{Measurements}

\section{Dependent variable}

A proxy index for access to primary care was created based on healthcare utilization variables including health insurance coverage, timeliness of care, distance to the nearest primary care center, availability of essential healthcare services, affordability, acceptability, quality of care, and treatment procedure. The access index was finally computed using principal component analysis (PCA) and varimax rotation method. Principal components are weighted averages of the variables used to construct them. The computed index was finally used to classify the sampled households into three categories (tertiles): lowest, middle, and highest. The first eigenvalue of the PCA was 1.72 and the proportion of variance explained by the first three components was $58 \%$.

\section{Independent variables}

We conceptualized two categories of predictor variables (individual and household-level factors) from Andersen and Newman's behavioural model of health service utilization [23]. Individual factors comprised of age, marital status, and level of education. Household-level factors comprised of the sex of the household head, ethnicity, household size, wealth tertile, the primary source of care, and quarterly out-of-pocket (OOP) expenditure on healthcare. The quarterly OOP comprised of the total expenditures on consultation, diagnostics and laboratory tests, medication, emergency, and/or specialized care (such as dental care) in the three months preceding this survey. It was grouped into four categories: those who spent $\leq$ USD 5, between USD 5 and USD 9.9, between USD10 and USD 29.9 and $\geq$ USD 30. A wealth index was generated using PCA from the socio-economic variables including type of dwelling, ownership of the dwelling, construction materials of the dwelling, source of cooking fuel, the source of lighting fuel, household possessions/goods, the source of water for household consumption and type of sanitation facility. The households were grouped into tertiles based on the generated wealth index (lowest, middle, and highest).

\section{Data analysis}

The outcome variable for this study is access to primary healthcare services. Descriptive statistics were used to summarize the background characteristics of the respondents and the frequency distribution of access to primary care with individual and household-level factors. The outcome variable assumes an increasing order. Hence a multivariate ordered logistic regression was conducted. We fitted a proportional odds model; however, following the Brant test, we found that the critical assumption of parallel slopes ${ }^{1}$ was violated in some of the covariates (age group, education level, and primary source of care). Consequently, we implemented a partial proportional odds model which is less restrictive, and relaxes the proportional odds assumption, allowing the effect of the explanatory covariates to vary [24]. More information on the partial proportional odds model is available in numerous sources [24, 25]. All explanatory variables in the unadjusted partial proportional odds model that were associated with the outcome were added to the adjusted partial proportional odds model. The results of the multivariate logistic regression compare a continuum of households ranging from those that have low access, moderate access to those that have highest access to primary healthcare. We used Stata version 15.1 and statistical significance was defined as a $p$-value less than 0.05 (2-sided). The gologit2 [25] Stata command was used to fit the partial proportional odds model.

\section{Ethical considerations}

The protocol for this study was reviewed and approved by the African Medical and Research Foundation based in Nairobi, Kenya (P482/2018). Written informed consent was sought from all respondents prior to participation.

\section{Results \\ Socio-demographic characteristics of the respondents} Table 1 shows the demographic characteristics of the respondents. Male respondents constituted a slightly

${ }^{1}$ One assumption underlying the ordered logistic is the parallel lines assumption/proportional odds which posits that the relationship between each pair of the outcome groups is the same. 
Table 1 Socio-demographic characteristics of the respondents

\begin{tabular}{|c|c|c|}
\hline & Number & Percent \\
\hline \multicolumn{3}{|l|}{ Sex } \\
\hline Male & 155 & 51.7 \\
\hline Female & 145 & 48.3 \\
\hline \multicolumn{3}{|l|}{ Age group } \\
\hline $18-29$ & 115 & 38.3 \\
\hline $30-44$ & 133 & 44.3 \\
\hline $45-59$ & 42 & 14.0 \\
\hline 60 and above & 10 & 3.3 \\
\hline \multicolumn{3}{|l|}{ Marital status } \\
\hline Married/living together & 171 & 57.0 \\
\hline Divorced/ separated & 43 & 14.3 \\
\hline Widowed & 8 & 2.7 \\
\hline Never married/never lived together & 57 & 19.0 \\
\hline Others & 21 & 7.0 \\
\hline \multicolumn{3}{|l|}{ Level of education } \\
\hline No formal schooling & 4 & 1.3 \\
\hline Primary & 120 & 40.0 \\
\hline Secondary & 156 & 52.0 \\
\hline College/university & 20 & 6.7 \\
\hline \multicolumn{3}{|l|}{ Religion } \\
\hline Roman catholic & 96 & 32.0 \\
\hline Protestants & 178 & 59.3 \\
\hline Other Christians. & 6 & 2.0 \\
\hline Muslim & 9 & 3.0 \\
\hline No religion & 11 & 3.7 \\
\hline \multicolumn{3}{|l|}{ Household size } \\
\hline $1-3$ & 183 & 61.0 \\
\hline $4-6$ & 104 & 34.0 \\
\hline $7+$ & 13 & 4.3 \\
\hline \multicolumn{3}{|l|}{ Wealth tertile } \\
\hline Lowest & 100 & 33.3 \\
\hline Middle & 100 & 33.3 \\
\hline Highest & 100 & 33.3 \\
\hline \multicolumn{3}{|l|}{ Health insurance coverage } \\
\hline Yes & 129 & 43.0 \\
\hline No & 171 & 57.0 \\
\hline
\end{tabular}

higher proportion of the sample (52\%) compared to females (48\%). Approximately $44 \%$ of the respondents were aged between 30 and 44 years, 38\% for $18-29$ years, $14 \%$ for $45-59$ years, and $3 \%$ for 60 years and above. The majority of the respondents (57\%) were either married or living together with their partners. About $52 \%$ of the respondents had completed secondary education, $40 \%$ primary education, $7 \%$ tertiary education and $1.3 \%$ had no formal schooling. The majority of the respondents
(59\%) were Protestants, others included Catholics (32\%), Muslims (3\%), other Christians (2\%), and, no religion $(4 \%)$. Most of the households (61\%) consisted of between one and three members. About $33 \%$ of the respondents were in the lowest, moderate, and highest wealth tertile respectively.

Distribution of the respondents by access to primary care Table 2 shows the distribution of respondents by access tertile. The age group 45 years and above had the highest percentage of respondents in the highest access tertile at $38.5 \%$. A higher percentage of households headed by males $(38.2 \%)$ were in the highest access tertile compared to those headed by females (16.4\%). Respondents with primary level of education constituted the highest percentage of those in the highest access tertile at $36.3 \%$. Households with 1-3 members had the highest proportion of those in the highest access tertile at 36\%. Respondents whose main source of income is casual work constituted the highest percentage of those in the highest access tertile at $35.5 \%$.

Respondents in the highest wealth tertile constituted the highest percentage of those in the highest access tertile at $37 \%$. Respondents whose average out-of-pocket healthcare expenditure in the three months preceding the survey was below USD 5 constituted the highest percentage of those in the highest access tertile at 39\%. Respondents whose ethnic background is Luo constituted the highest percentage of those in the highest access tertile at $47 \%$. A higher percentage of respondents who sought care from a private health facility $(50 \%)$ were in the highest access tertile compared to those who sought care from a public health facility $(14.8 \%)$.

\section{Factors associated with access to primary care}

We first conducted the Brant test of the parallel lines assumption/proportional odds on the ordered logistic regression. The Brant test suggests that this hypothesis is violated $(\chi 2=20.95, p$-value $=0.051)$. Hence, we reported the results of the multivariate analysis using the generalized ordinal logistic regression in Table 3.

The odds of being the combined categories of moderate and highest access tertiles versus lowest were about twice higher for male-headed households than femaleheaded households, other variables held constant (AOR 2.07 [95\% CI 1.14-3.76]; $p<.05$ ). In the same vein, the odds of being in the highest access tertile versus the combined categories of lowest and moderate access tertile were three times higher for male than female-headed households, given the other variables are held constant (AOR 3.05 [95\% CI 1.47-6.37]; $p<.05$ ).

The odds of being in the combined moderate and highest access tertiles versus lowest were $76 \%$ lower for households with an average quarterly out-of-pocket healthcare 
Table 2 Distribution of respondents by access to primary care

\begin{tabular}{|c|c|c|c|c|}
\hline & $\mathrm{N}$ & Access tertil & & \\
\hline & & (\%) lowest & (\%) moderate & (\%) highest \\
\hline Age group & & & & \\
\hline $18-29$ & 115 & 33.91 & 28.70 & 37.39 \\
\hline $30-44$ & 133 & 37.59 & 34.59 & 27.82 \\
\hline 45 and above & 52 & 25.00 & 36.54 & 38.46 \\
\hline Sex of the household head ${ }^{* *}$ & & & & \\
\hline Male & 233 & 29.18 & 32.62 & 38.20 \\
\hline Female & 67 & 50.75 & 32.84 & 16.42 \\
\hline Marital status & & & & \\
\hline Married/living together & 171 & 33.33 & 31.58 & 35.09 \\
\hline Divorced/separated/widowed & 51 & 43.14 & 35.29 & 21.57 \\
\hline Never married & 78 & 29.49 & 33.33 & 37.18 \\
\hline Education & & & & \\
\hline Primary and below & 124 & 33.87 & 29.84 & 36.29 \\
\hline Secondary & 156 & 34.62 & 32.69 & 32.69 \\
\hline Tertiary & 20 & 30.00 & 50.00 & 20.00 \\
\hline Household size & & & & \\
\hline $1-3$ & 183 & 29.51 & 34.43 & 36.07 \\
\hline 4 and above & 117 & 41.03 & 29.91 & 29.06 \\
\hline Occupation & & & & \\
\hline Employed worker & 65 & 38.46 & 26.15 & 35.38 \\
\hline Casual worker & 141 & 25.53 & 39.01 & 35.46 \\
\hline Trader & 73 & 39.73 & 32.88 & 27.40 \\
\hline Unemployed & 21 & 57.14 & 9.52 & 33.33 \\
\hline Wealth tertile & & & & \\
\hline Lowest & 100 & 30.00 & 35.00 & 35.00 \\
\hline Middle & 100 & 39.00 & 33.00 & 28.00 \\
\hline Highest & 100 & 33.00 & 30.00 & 37.00 \\
\hline Quarterly healthcare expenditu & & & & \\
\hline$\leq$ USD 5 & 143 & 22.38 & 39.16 & 38.46 \\
\hline USD 5- USD 999 & 42 & 45.24 & 23.81 & 30.95 \\
\hline USD10- USD 29.9 & 49 & 36.73 & 30.61 & 32.65 \\
\hline$\geq$ USD 30 & 66 & 50.00 & 25.76 & 24.24 \\
\hline Ethnicity & & & & \\
\hline Kamba & 107 & 28.97 & 31.78 & 39.25 \\
\hline Kikuyu & 92 & 35.87 & 30.43 & 33.70 \\
\hline Kisii & 20 & 50.00 & 30.00 & 20.00 \\
\hline Luhya & 45 & 35.56 & 42.22 & 22.22 \\
\hline Luo & 17 & 23.53 & 29.41 & 47.06 \\
\hline${ }^{1}$ Others & 19 & 42.11 & 31.58 & 26.32 \\
\hline Source of primary care ${ }^{* *}$ & & & & \\
\hline Public & 142 & 46.48 & 38.73 & 14.79 \\
\hline Private & 158 & 22.78 & 27.22 & 50.00 \\
\hline Total & 300 & 34.00 & 32.67 & 33.33 \\
\hline
\end{tabular}

Cl 95\% confidence interval. *significant at $p<0.05,{ }^{*}$ significant at $p<0.001,{ }^{1}$ Other tribes comprise Borana, Taita, and Garre 
Table 3 Generalized ordinal logistic regression of factors associated with access to primary care

\begin{tabular}{|c|c|c|c|c|c|c|c|}
\hline \multirow[t]{2}{*}{ Access tertile } & & \multicolumn{3}{|c|}{ Unadjusted Model } & \multicolumn{3}{|c|}{ Adjusted Model } \\
\hline & & \multirow[t]{2}{*}{$\overline{\mathrm{OR}}$} & \multicolumn{2}{|c|}{$95 \% \mathrm{Cl}$} & \multirow[t]{2}{*}{$\overline{\mathrm{OR}}$} & \multicolumn{2}{|c|}{$95 \% \mathrm{Cl}$} \\
\hline \multicolumn{6}{|l|}{ Lowest } & & \\
\hline Sex of the household head (Ref: female) & Male & $2.50^{*}$ & 1.43 & 4.36 & $2.07^{*}$ & 1.14 & 3.76 \\
\hline Quarterly healthcare expenditure & USD 5- USD 999 & $0.35^{*}$ & 0.17 & 0.72 & $0.27^{*}$ & 0.13 & 0.59 \\
\hline \multirow[t]{2}{*}{ (Ref: $\leq$ USD 5) } & USD 10- USD 29.9 & 0.50 & 0.25 & 1.00 & $0.39^{*}$ & 0.18 & 0.83 \\
\hline & $\geq$ USD 30 & $0.29^{* *}$ & 0.15 & 0.54 & $0.24^{* *}$ & 0.12 & 0.47 \\
\hline Source of primary care (Ref: public) & Private & $2.94^{* *}$ & 1.79 & 4.84 & $3.56^{* *}$ & 2.07 & 6.11 \\
\hline \multirow[t]{3}{*}{ Age group (Ref: 18-29) } & $30-44$ & 0.85 & 0.51 & 1.44 & & & \\
\hline & $45-59$ & 1.28 & 0.59 & 2.78 & & & \\
\hline & $>60$ & 4.62 & 0.56 & 37.78 & & & \\
\hline \multirow[t]{2}{*}{ Education (Ref: primary) } & Secondary & 0.97 & 0.59 & 1.59 & & & \\
\hline & Tertiary & 1.20 & 0.43 & 3.33 & & & \\
\hline Household size (Ref: 1 to 3 ) & $4+$ & 0.60 & 0.37 & 0.98 & & & \\
\hline Marital status (Ref: married/living together) & Single/divorced/separated/widowed & 0.93 & 0.58 & 1.51 & & & \\
\hline \multirow[t]{2}{*}{ Wealth tertile (Ref: lowest) } & Middle & 0.67 & 0.37 & 1.21 & & & \\
\hline & Highest & 0.87 & 0.48 & 1.58 & & & \\
\hline \multirow[t]{5}{*}{ Ethnicity (Ref: Kamba) } & Kikuyu & 0.73 & 0.40 & 1.32 & & & \\
\hline & Kisii & 0.41 & 0.15 & 1.08 & & & \\
\hline & Luhya & 0.74 & 0.35 & 1.55 & & & \\
\hline & Luo & 1.33 & 0.40 & 4.38 & & & \\
\hline & Others & 0.56 & 0.21 & 1.53 & & & \\
\hline \multicolumn{8}{|l|}{ Moderate } \\
\hline Sex of the household head (Ref: female) & Male & $2.50^{*}$ & 1.43 & 4.36 & $3.05^{*}$ & 1.47 & 6.37 \\
\hline Quarterly healthcare expenditure & USD 5- USD 999 & 0.72 & 0.34 & 1.50 & 0.51 & 0.23 & 1.13 \\
\hline \multirow[t]{2}{*}{ 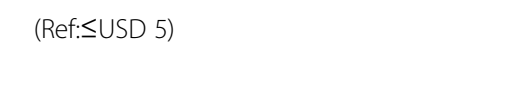 } & USD 10- USD 29.9 & 0.78 & 0.39 & 1.54 & 0.57 & 0.27 & 1.21 \\
\hline & $\geq$ USD 30 & $0.51^{*}$ & 0.27 & 0.99 & $0.36^{*}$ & 0.18 & 0.74 \\
\hline Source of primary care (Ref: public) & Private & $5.76^{* *}$ & 3.30 & 10.07 & $6.64^{* *}$ & 3.67 & 12.01 \\
\hline \multirow[t]{3}{*}{ Age group (Ref: 18-29) } & $30-44$ & 0.65 & 0.38 & 1.10 & & & \\
\hline & $45-59$ & 1.26 & 0.61 & 2.58 & & & \\
\hline & $>60$ & 0.42 & 0.08 & 2.06 & & & \\
\hline \multirow[t]{2}{*}{ Education (Ref: primary) } & Secondary & 0.85 & 0.52 & 1.40 & & & \\
\hline & Tertiary & 0.44 & 0.14 & 1.39 & & & \\
\hline Household size (Ref: 1 to 3 ) & $4+$ & 0.73 & 0.44 & 1.20 & & & \\
\hline Marital status (Ref: married/living together) & Divorced/separated/widowed & 0.83 & 0.51 & 1.35 & & & \\
\hline \multirow[t]{2}{*}{ Wealth tertile (Ref: lowest) } & Middle & 0.72 & 0.40 & 1.32 & & & \\
\hline & Highest & 1.09 & 0.61 & 1.94 & & & \\
\hline \multirow[t]{5}{*}{ Ethnicity (Ref: Kamba) } & Kikuyu & 0.73 & 0.40 & 1.32 & & & \\
\hline & Kisii & 0.41 & 0.15 & 1.08 & & & \\
\hline & Luhya & 0.74 & 0.35 & 1.55 & & & \\
\hline & Luo & 1.33 & 0.40 & 4.38 & & & \\
\hline & Others & 0.56 & 0.21 & 1.53 & & & \\
\hline
\end{tabular}


expenditure of USD 30 and above compared to those with a quarterly expenditure of less than USD 5 , given that other variables are held constant (AOR 0.24 [95\% CI 0.12-0.47]; $p<.001$ ). Likewise, the odds of being in the highest versus combined categories of lowest and moderate access tertile were $64 \%$ lower for households with an average quarterly out-of-pocket healthcare expenditure of USD 30 and above compared to those with a quarterly expenditure of less than USD 5, given the other variables are held constant (AOR 0.36 [95\% CI 0.18-0.74]; $p<.05$ ).

The odds of being in the combined categories of moderate and highest access tertiles versus lowest access tertile were about four times higher for households that sought care from private facilities compared to the public, given the other variables are held constant (AOR 3.56 [95\% CI 2.07-6.11]; $p<.001$ ). In the same vein, the odds of being in the combined categories of lowest and moderate access tertile versus highest access tertile were about seven times higher for households that sought care from private facilities compared to public, given the other variables are held constant (AOR 6.64 [95\% CI 3.67-12.01]; $p<.001$ ).

\section{Discussion}

In this study, we assessed the level of access to primary healthcare services and associated factors in urban slums in Nairobi-Kenya. Our findings revealed that seeking care from a public primary care facility, living in a household headed by a female, and paying out-of-pocket for healthcare services are significantly associated with low access to primary care.

Our results suggest a systematic disadvantage of female versus male-headed households in access to primary care. Previous studies have also consistently revealed widespread gender differences in access to primary care [26-28]. Several explanations have been offered. These disparities may be associated with gender inequalities in access to health insurance coverage [29, 30]. Our findings are consistent with the results of the 2013 Kenya Household Healthcare Expenditure and Utilization Survey (KHEUS) which suggests that women are more likely to have poor access to primary healthcare services due to low health insurance coverage [31]. In general, the most important determinants of health insurance coverage are employment-related factors and income $[16,29,32]$. A possible explanation for these results could be the existence of gender differences in job opportunities with women more likely to engage in informal employment with a lack of entitlements such as health insurance than men [28].

Our finding that paying out-of-pocket for healthcare services was significantly associated with low access to primary care is consistent with evidence from a number of recent studies [33-36]. In particular, poor financial protection in low resource settings is attributable to inadequate funding, fragmentation of healthcare resources, and inadequate health insurance coverage [16]. Similar to the findings of our study, previous studies have also shown that direct OOP costs place a huge burden of bearing the costs of illness to the sick person and their households, and is therefore, a major contributor to inequities [37-41]. Providing financial risk protection to reduce OOP health expenditure as envisaged in the Sustainable Development Goals and UHC agendas are critical to improving access to primary healthcare in resource-poor urban settings.

Similar to previous studies [42-44], our results suggest higher odds of low access to primary care among households that sought primary healthcare services from public facilities compared to private. A plausible explanation for these findings could be due to in part the gaps in basic health infrastructure, medical equipment, availability of drugs, and other essential supplies in public primary care facilities $[11,39,45,46]$. If not addressed, this lack of inputs may grossly affect the accessibility of primary services and jeopardize the efforts towards achieving UHC. The results of the current study findings reinforce the need for the Kenyan government to address the weaknesses of the public health sector and regulate the quality of public health facilities in urban slum settlements by providing technical support to bring quality healthcare services closer to slum populations.

Our findings have three key policy implications. First, within the healthcare system in Viwandani slums in Nairobi, Kenya, there is an urgent need for implementation of policies and programs that take into account the gender disparity in access to primary care. Second, there is a need to scale up efforts for expanding health insurance coverage in the slum communities to cushion households against OOP expenditures. Third, proper mechanisms should be developed to regularly monitor the quality of healthcare services offered by public facilities in urban slums by the relevant authorities. Technical support is also required for them to improve the quality of healthcare services.

\section{Limitations}

The respondents for this study comprised adults aged 18 years and over who were either household heads or permanent household members, therefore, the possibility of recall bias or slight variations in the responses provided by the household heads, their spouses, or other credible adult household members cannot be overemphasized. The study did not disaggregate health expenditure into the various components of direct and indirect healthcare spending. There is therefore little room to draw conclusive arguments on costs such as transport to access healthcare, time lost from work and other informal costs which households may incur in the process of seeking access to care. In addition, the fact that the 
study was conducted in one urban slum settlement may have a bearing on its generalizability to other urban slums in Kenya. Despite these limitations, our study findings provide useful insights on the level of access to primary healthcare services and associated factors in urban slums in Nairobi, Kenya and serve as a basis for more rigorous investigations in other urban slum settings in Kenya and sub-Saharan Africa.

\section{Conclusions}

This study shows that access to primary healthcare services for slum residents is poor and varies by the gender of the household head, source of primary care and OOP healthcare expenditure. Our study provides important results particularly highlighting the lower access to primary healthcare among female-headed households. Multiple approaches to primary healthcare access are needed to address this issue among slum residents. Therefore, policies that encourage economic growth in femaleheaded households are likely to create economic empowerment and improve access to primary healthcare in these settings. Similarly, public programs that offer protection against out-of-pocket spending are likely to improve access to primary healthcare. In addition, public health facilities need to improve the quality services provided.

\section{Abbreviations}

AOR: Adjusted odds ratio; Cl: Confidence interval; KHEUS: Kenya household healthcare expenditure and utilization survey; LMIC: Low and middle-income countries; NUHDSS: Nairobi urban health demographic surveillance system; OOP: Out of pocket payment; PCA: Principal component analysis;

UHC: Universal health coverage; USD: United States Dollar

\section{Acknowledgments}

Not applicable.

\section{Authors' contributions}

POO conceptualized the study, reviewed literature and contributed to data analysis. SM, EW, HD, MKM, PMK and BM made substantive contributions to the conceptualization of the study and reviewed the manuscript. All authors read and approved the final manuscript.

\section{Funding}

This research received no specific grant from any funding agency in the public, commercial or not-for-profit sectors.

\section{Availability of data and materials}

Data are available upon reasonable request. Study materials and deidentified data that support the findings in this study are available by contacting Shukri Mohamed at the African Population and Health Research Center in Kenya via email address smohamed@aphrc.org.

\section{Ethics approval and consent to participate}

This study was approved by the Ethical Review Board of AMREF Foundation based in Nairobi, Kenya (reference number: P482/2018). The respondents went through an informed consent process and their participation was voluntary and anonymous. Written consent was provided before participation.

\section{Consent for publication}

Not required.

\section{Competing interests}

The authors declare that they have no competing interest.

Received: 23 October 2019 Accepted: 12 June 2020

Published online: 22 June 2020

\section{References}

1. Glass DP, et al. The impact of improving access to primary care. J Eval Clin Pract. 2017;23(6):1451-8.

2. Gulliford M. Access to primary care and public health. Lancet Public Health. 2017:2(12): :532-3.

3. Jamison DT, et al. Universal health coverage and intersectoral action for health: key messages from disease control priorities, 3rd edition. Lancet. 2018;391(10125):1108-20

4. Organization, W.H., From alma Ata to the year 2000: reflections at the midpoint. 1988

5. Ji JS, Chen L. UHC presents universal challenges. Health Syst Reform. 2016; 2(1):11-4.

6. Kruk ME, et al. The contribution of primary care to health and health systems in low-and middle-income countries: a critical review of major primary care initiatives. Soc Sci Med. 2010;70(6):904-11.

7. Moreno-Serra R, Smith PC. Does progress towards universal health coverage improve population health? Lancet. 2012;380(9845):917-23.

8. Fullman N, Lozano R. Towards a meaningful measure of universal health coverage for the next billion. Lancet Glob Health. 2018;6(2):e122-3.

9. UN-HABITAT. The State of African Cities 2008 - A Framework for Addressing Urban Challenges in Africa. Nairobi: UN-HABITAT; 2008.

10. UN-HABITAT. The State of African Cities 2010: Governance, Inequality and Urban Land Markets. Nairobi: United Nations; 2010.

11. Chuma J, Gilson L, Molyneux C. Treatment-seeking behaviour, cost burdens and coping strategies among rural and urban households in coastal Kenya: an equity analysis. Tropical Med Int Health. 2007;12(5):673-86.

12. Kyobutungi C, et al. The burden of disease profile of residents of Nairobi's slums: results from a demographic surveillance system. Popul Health Metrics. 2008:6(1):1.

13. Muriithi MK. The determinants of health-seeking behavior in a Nairobi slum, Kenya. Eur Sci J. 2013;9:151-64.

14. Ziraba AK, et al. The state of emergency obstetric care services in Nairobi informal settlements and environs: results from a maternity health facility survey. BMC Health Serv Res. 2009;9(1):46.

15. Amendah DD, Buigut S, Mohamed S. Coping strategies among urban poor: evidence from Nairobi, Kenya. PloS one. 2014;9(1):e83428.

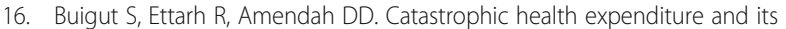
determinants in Kenya slum communities. Int J Equity Health. 2015;14:46.

17. Ezeh A, et al. The history, geography, and sociology of slums and the health problems of people who live in slums. Lancet. 2017;389(10068):547-58.

18. Fotso JC, Mukiira C. Perceived quality of and access to care among poor urban women in Kenya and their utilization of delivery care: harnessing the potential of private clinics? Health Policy Plan. 2011;27(6):505-15.

19. Penchansky R, Thomas JW. The concept of access: definition and relationship to consumer satisfaction. Med Care. 1981;19(2):127-40.

20. Otieno PO, Wambiya EOA, Mohamed SF, Donfouet HPP, Mutua MK. Prevalence and factors associated with health insurance coverage in resource-poor urban settings in Nairobi, Kenya: a cross-sectional study. BMJ Open. 2019;9(12):2.

21. Chimezie RO. A case study of primary healthcare services in Isu, Nigeria. In: Walden Dissertations and Doctoral Studies; 2011.

22. PaköZ MZ, Yüzer MA. Access to healthcare: A field survey in Istanbul. A| Z ITU J Faculty Architecture. 2014;11(2):271-90.

23. Andersen R, Newman JF. Societal and individual determinants of medical care utilization in the United States. The Milbank Memorial Fund Quarterly. 1973;51:95-124.

24. Ananth CV, Kleinbaum DG. Regression models for ordinal responses: a review of methods and applications. Int J Epidemiol. 1997;26(6):1323-33.

25. Williams R. Generalized ordered logit/partial proportional odds models for ordinal dependent variables. Stata J. 2006;6(1):58-82.

26. Iyer A, Sen G, Östlin P. The intersections of gender and class in health status and health care. Global Public Health. 2008;3(S1):13-24.

27. Merzel C. Gender differences in health care access indicators in an urban, low-income community. Am J Public Health. 2000;90(6):909. 
28. Suda C. Gender disparities in the Kenyan labour market. Nord J Afr Stud. 2002;11(3):21.

29. Kimani JK, et al. Determinants of health insurance ownership among women in Kenya: evidence from the 2008-09 Kenya demographic and health survey. Int J Equity Health. 2014;13(1):27.

30. Witter $\mathrm{S}$, et al. Minding the gaps: health financing, universal health coverage and gender. Health Policy Planning. 2017;32(suppl_5):v4-v12.

31. MOH. 2013 Kenya Household Health Expenditure and Utilisation Survey. Nairobi: Government of Kenya; 2014.

32. Mathauer I, Schmidt JO, Wenyaa M. Extending social health insurance to the informal sector in Kenya. An assessment of factors affecting demand. Int J Health Plann Manag. 2008;23(1):51-68.

33. Ciapponi A, et al. Delivery arrangements for health systems in low-income countries: an overview of systematic reviews. Cochrane Database Syst Rev. 2017;9:Cd011083.

34. Herrera CA, et al. Governance arrangements for health systems in lowincome countries: an overview of systematic reviews. Cochrane Database Syst Rev. 2017:9:Cd011085

35. Pantoja T, et al. Implementation strategies for health systems in low-income countries: an overview of systematic reviews. Cochrane Database Syst Rev. 2017;9:Cd011086.

36. Wiysonge CS, et al. Financial arrangements for health systems in lowincome countries: an overview of systematic reviews. Cochrane Database Syst Rev. 2017:9:Cd011084.

37. Barasa EW, Maina T, Ravishankar N. Assessing the impoverishing effects, and factors associated with the incidence of catastrophic health care payments in Kenya. Int J Equity Health. 2017;16(1):31.

38. Bonfrer I, Gustafsson-Wright E. Health shocks, coping strategies and foregone healthcare among agricultural households in Kenya. Glob Public Health. 2017;12(11):1369-90.

39. Barasa E, Nguhiu P, McIntyre D. Measuring progress towards Sustainable Development Goal 3.8 on universal health coverage in Kenya. BMJ Glob Health. 2018;3(3):e000904.

40. Maina JM, Kithuka P, Tororei S. Perceptions and uptake of health insurance for maternal care in rural Kenya: a cross sectional study. Pan Afr Med J. 2016;23:125

41. Atake EH, Amendah DD. Porous safety net: catastrophic health expenditure and its determinants among insured households in Togo. BMC Health Serv Res. 2018:18(1):175.

42. Acharya LB, Cleland J. Maternal and child health services in rural Nepal: does access or quality matter more? Health Policy Plan. 2000;15(2):223-9.

43. Chakraborty N, et al. Determinants of the use of maternal health services in rural Bangladesh. Health Promot Int. 2003;18(4):327-37.

44. Falkingham J, Akkazieva B, Baschieri A. Trends in out-of-pocket payments for health care in Kyrgyzstan, 2001-2007. Health Policy Plan. 2010;25(5):427-36.

45. Barasa E, et al. Kenya National Hospital Insurance Fund Reforms: implications and lessons for universal health coverage. Health Syst Reform. 2018;4(4):346-61

46. Chuma J, Maina T. Catastrophic health care spending and impoverishment in Kenya. BMC Health Serv Res. 2012;12(1):413.

\section{Publisher's Note}

Springer Nature remains neutral with regard to jurisdictional claims in published maps and institutional affiliations.

\section{Ready to submit your research? Choose BMC and benefit from:}

- fast, convenient online submission

- thorough peer review by experienced researchers in your field

- rapid publication on acceptance

- support for research data, including large and complex data types

- gold Open Access which fosters wider collaboration and increased citations

- maximum visibility for your research: over $100 \mathrm{M}$ website views per year

At $\mathrm{BMC}$, research is always in progress.

Learn more biomedcentral.com/submissions 